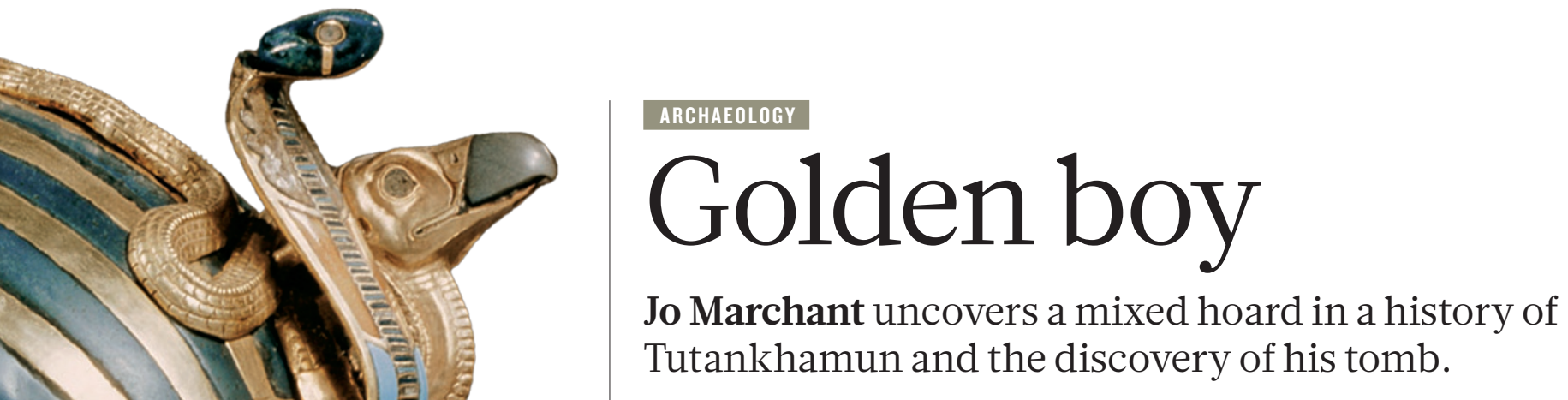

A rchaeological finds don't come much more impressive than the contents of Tutankhamun's tomb. When Howard Carter glimpsed those "wonderful things" in 1922, his discovery captivated the world - inspiring everything from jewellery and music to a proposal to name an extension to the London Underground Tootancamden, because it would pass through Tooting and Camden Town. Tutmania resurfaced in the 1970 s, when a record-breaking touring exhibition of the burial goods radically changed the museum business.

Joyce Tyldesley's Tutankhamen rides a more recent wave of interest, including two major scientific studies of Tutankhamun's mummy, a new museum tour and a string of high-profile documentaries. Tyldesley, an Egyptologist, has written not a biography of the boy king, but a broad history of the discovery.

Tyldesley divides her book into two sections. The first, and meatiest, is concerned with what we know of the king himself - including the

"Tutankhamun's youthful demise set the scene for endless speculation and conspiracy theories." research on his remains. The second section addresses the cultural construct that has sprung up around him since the discovery, from archaeological conspiracies to the infamous curse.

Today, Tutankhamun is ancient Egypt's best-known ruler, his golden funerary mask recognized around the world. But in his lifetime, Tyldesley tells us, he was a minor king who came to the throne as a child and ruled for a decade at most, dying at around the age of 18 . The only pharaoh's tomb ever discovered nearly intact (although it was robbed twice in antiquity), his resting place yielded a breathtaking 5,398 objects, from golden thrones and chariots to a lock of his grandmother's hair.

But Tutankhamun's fame rests on more than that otherworldly cornucopia. He belongs to the romanticized Amarna period, which began when his predecessor,

Tutankhamun's burial mask has become an icon.
Akhenaten, threw out Egypt's traditional religion to worship only Aten, the Sun disc. And Tutankhamun's youthful demise set the scene for endless speculation and conspiracy theories.

Tyldesley's account of Carter's momentous find and the clearance of the tomb is brought to life with contemporary quotes and colourful details.

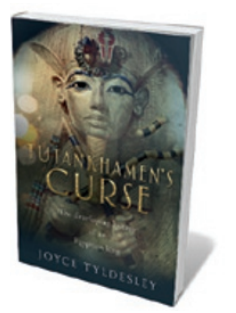

Tutankhamen: The Search for an Egyptian King JOYCE TYLDESLEY Basic Books/Profile: 2012. $336 \mathrm{pp}$. $\$ 29.99 / £ 18.99$

She tells how, shortly after the discovery, Carter bought almost 6 kilometres of cotton wool and several thousand light bulbs in Luxor, then converted burial chambers near Tutankhamun's into a photographic darkroom, laboratory and "luncheon tomb".

The story continues with the unwrapping and autopsy of Tutankhamun's mummy, and the scientific analyses done on it since. The findings of the original autopsy are described - from the king's penis (5 centimetres long, bound in the erect position) to a large scab on his left cheek. But Tyldesley's treatment of more recent analyses is disappointing. Scans in 2005 suggested that the boy king had a broken leg, and DNA tests in 2010 provided evidence that he was inbred, and died of malaria. These studies are the subject of intense debate among experts and are the only new scientific material in the book, yet they are skipped over in a few cursory paragraphs.

Instead, there is a lengthy discussion of the Egyptological evidence for Tutankhamun's family relationships, with tomb paintings and graffiti suggesting an exhausting eight candidates for the pharaoh's mother. The rather unsatisfying conclusion seems to be that we can't say much more about Tutankhamun's life than Carter could in the 1920s.

We still don't know who his parents were, although skull shapes and blood groups suggest that he was closely related to a mummy found in a nearby tomb - who may or may not be Akhenaten. Nor do we know how he died. Tyldesley includes a brief suggested biography anyway, plumping for the fairly safe choices of Akhenaten and a prominent 
wife called Kiya as Tutankhamun's parents.

After hundreds of books on this subject, the promise on the cover that Tyldesley is "shedding new light" on the boy king was always going to be hard to keep. But she is such a gifted storyteller that perhaps it doesn't matter. Her writing is crystal-clear and charmingly irreverent - she describes Akhenaten's revolutionary reign as " 17 years of royal navelgazing" - and she shares intimate anecdotes, such as how Carter and his patron, Lord Carnarvon, broke into the burial chamber ahead of the official opening, covering up their entry point with a basket lid. She puts what little we know about Tutankhamun into context, giving a fascinating discussion of the discovery's social history.

So how does Tyldesley think Tutankhamun died? She dismisses murder, and speculates that the teenager died in a hunting accident. She assigns particular significance to one of his most iconic possessions: the remains of an "ostrich-feather fan" inscribed with hunting scenes. Perhaps the king met his end in pursuit of these notoriously dangerous birds.

It is a nice idea, except that the fan may have nothing to do with ostriches. Tyldesley doesn't mention that in 1978, two US biologists who attended the touring exhibition realized that several animal-related objects from the tomb had been misdescribed by Egyptologists. From the feathers and hunting scenes on the fan, they concluded that Tutankhamun was actually chasing the smaller, and less deadly, Arabian bustard.

And there is the problem - and perhaps the eternal fascination - with this enigmatic king. The harder we look for answers, the deeper the mystery gets. a SEE COMMENT P.27

Jo Marchant is a freelance writer based in London. Her forthcoming book is on Tutankhamun's mummy. e-mail:jomarchant26@yahoo.co.uk

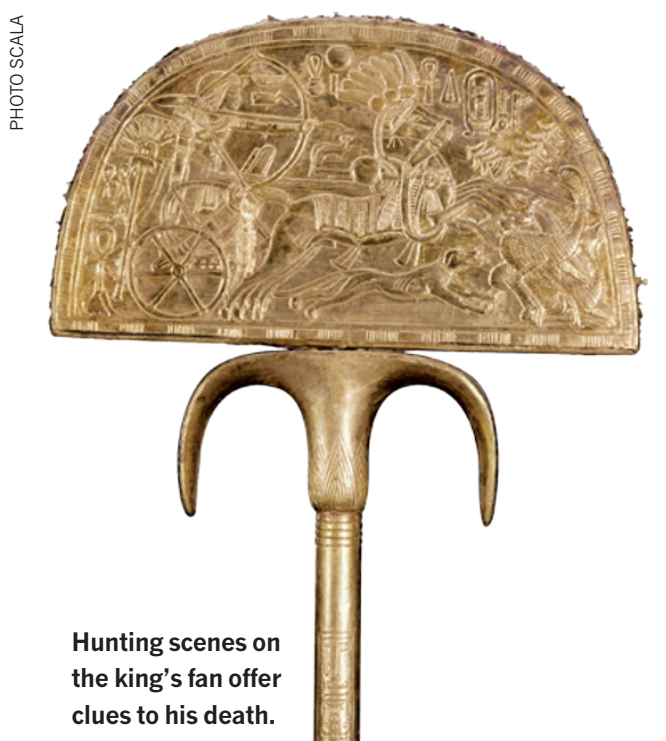

\section{Darkness made visible}

\section{Daniel Cressey reflects on a play that uses astronomy and medicine to probe what it means to see.}

$\mathrm{U}$ K theatre company Sound\&Fury takes a lab-like approach to its art. Fascinated by the effects of sensory immersion on audiences, it explores mental and physical frontiers - confined spaces in its nuclear-submarine drama Kursk, or the effects of anaesthetic on consciousness in Ether Frolics. Total or partial darkness has featured in several of the company's productions, including its latest offering, the compelling one-man play Going Dark.

Sound\&Fury's previous dark dramas have taken audiences from the battlefields of ancient Troy (War Music) to a whalers' lifeboat drifting around an unforgiving Pacific (The Watery Part of the World). In Going Dark - which completes a UK tour this month at London's Young Vic theatre blindness, hallucinations and astronomy are used to illuminating effect.

Audience members find themselves peering into a planetarium. Under a projection of the Milky Way and often in darkness, this is an exploration of sight through vastly different lenses: the human eye, and the giant telescope arrays through which astronomers access the Universe.

The planetarium's science communicator, Max (played by John Mackay), is diagnosed early on with retinitis pigmentosa, an eye condition that can lead to blindness and hallucinations. He gradually becomes unable to see his own son - or the constellations, real or recreated, that are the focus of his life.

There is a scientific edge to the play. Hattie Naylor's script bristles with astronomical facts, and Dominic ffytche of the King's College London Institute of Psychiatry advised on Max's hallucinations. Co-director Tom Espiner developed a lay grasp of astronomy as a resident artist in the physics and astronomy departments at the University of Birmingham, UK, in 2007.

Max's creeping blindness is partly a commentary on a long-standing nemesis of stargazers, says Espiner: "We suffer from a kind of cultural myopia created by the 24-hour light pollution that hides the stars."

It is not just an inability to see, but

Going Dark DIRECTED BY TOM ESPINER, MARK ESPINER AND DAN JONES

Young Vic, London. 6-24 March. the very nature of how we see that Sound\&Fury delves into here. "The relationship between eye and brain is a kind of model for the way we

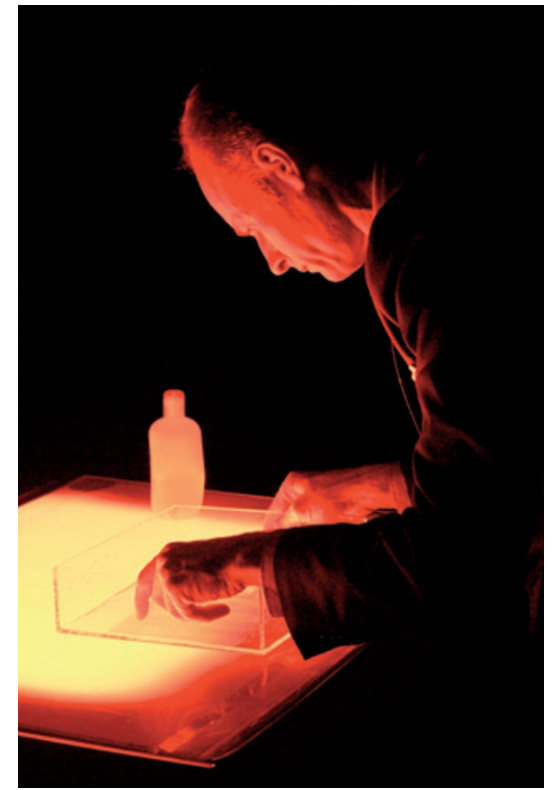

In Going Dark, John Mackay is a planetarium employee who loses his sight.

see the Universe," says Espiner. "Seeing is indirect, processed and interpreted by the brain before sight happens. Astronomical observation relies on huge instruments processing spectra of light far outside our perception into information we can process."

There are more teasers in the play's mining of metaphor. Max's bizarre hallucinations range from geometric shapes to human figures: the result of Charles Bonnet syndrome, a side effect of his medical condition. The audience experiences a taste of this when Max, looking into a mirror, sees his face horribly distorted - a vision that the audience shares, thanks to a tiny projector embedded in the set.

After the claustrophobia of Kursk, Going Dark moves the struggle to inner space an environment no less extreme. All told, this is a play that asks profound questions about humanity's anchor points in reality, says Espiner.

"What we thought we knew about the Universe changed after Galileo, and changed again with Hubble: the shape, size, levels of reality all shifted," he says. "As he loses his sight, Max has to negotiate a new universe: and we give the audience a sense of what that might be like."

Daniel Cressey is a reporter at Nature. 